\title{
Article \\ Hand and Abrasive Flow Polished Tungsten Carbide Die: Optimization of Surface Roughness, Polishing Time and Comparative Analysis in Wire Drawing
}

\author{
Raman Kumar ${ }^{1, * \mathbb{D}}$, Sehijpal Singh ${ }^{1}$, Vivek Aggarwal ${ }^{2}$, Sunpreet Singh ${ }^{3} \mathbb{D}$, Danil Yurievich Pimenov ${ }^{4} \mathbb{D}$, \\ Khaled Giasin ${ }^{5}$ (D) and Krzysztof Nadolny ${ }^{6}$ (D)
}

1 Department of Mechanical and Production Engineering, Guru Nanak Dev Engineering College, Ludhiana 141006, India; sehijpalsingh@yahoo.in

2 Department of Mechanical Engineering, IKGPTU Main Campus, Kapurthala 144603, India; dr.vivekaggarwal@ptu.ac.in

3 Department of Mechanical Engineering, Chandigarh University, Ghauruan 140413, India; snprt.singh@gmail.com

4 Department of Automated Mechanical Engineering, South Ural State University, Lenin Prosp. 76, 454080 Chelyabinsk, Russia; danil_u@rambler.ru

5 School of Mechanical and Design Engineering, University of Portsmouth, Portsmouth PO1 3DJ, UK; khaled.giasin@port.ac.uk

6 Department of Production Engineering, Koszalin University of Technology, Raclawicka 15-17, 75-620 Koszalin, Poland; krzysztof.nadolny@tu.koszalin.pl

* Correspondence: sehgal91@yahoo.co.in; Tel.: +91-985-5100-530

check for

updates

Citation: Kumar, R.; Singh, S.; Aggarwal, V.; Singh, S.; Pimenov, D.Y.; Giasin, K.; Nadolny, K. Hand and Abrasive Flow Polished Tungsten Carbide Die: Optimization of Surface Roughness, Polishing Time and Comparative Analysis in Wire Drawing. Materials 2022, 15, 1287. https://doi.org/10.3390/ ma15041287

Academic Editor: Irina Hussainova

Received: 14 December 2021

Accepted: 7 February 2022

Published: 9 February 2022

Publisher's Note: MDPI stays neutral with regard to jurisdictional claims in published maps and institutional affiliations.

Copyright: () 2022 by the authors. Licensee MDPI, Basel, Switzerland. This article is an open access article distributed under the terms and conditions of the Creative Commons Attribution (CC BY) license (https:// creativecommons.org/licenses/by/ $4.0 /)$.

\begin{abstract}
This research work highlights the benefits of abrasive flow polishing (AFP) applied to tungsten carbide dies compared with conventional hand polishing (HP). An indigenous experimental set-up for AFP was developed. The effect of prominent process parameters viz. extrusion pressure, number of cycles, and abrasive particle concentration on the final surface roughness, percentage improvement in surface roughness, and polishing time was investigated by Taguchi-designed experiments. The multi-objective optimization (MOO) was performed using the Taguchi-TOPSIS-Equal weight approach to find the respective optimized AFP parametric settings. A set of skilled operators performed the conventional HP of dies, and the best hand-polished (HPed) die was selected using the TOPSIS technique. The operational performance of the HPed dies and the abrasive flow polished (AFPed) dies were compared on the three-stage wire drawing operation. The results revealed that AFP's surface resulted in a better-quality surface than hand polishing with a $27.06 \%$ improvement in surface roughness. Furthermore, AFP can reduce the dependency on costly and tricky-to-locate skilled operators, with a reasonable amount of time saving (about 87.05\%). Overall, the study's findings show that abrasive flow polishing of dies is fast and cost-effective.
\end{abstract}

Keywords: abrasive flow polishing; hand polishing; surface roughness; wire drawing die; tungsten carbide; TOPSIS; polishing time; abrasive flow machining

\section{Introduction}

Polishing is a type of finishing operation performed after machining, and is essential to attain final surface quality and shape accuracy. It is generally performed on dies in metal forming and drawing operations to improve die life, quality of material processed, production time, and operation efficiency. However, inadequate polishing of the die leads to reduced die life and low product quality. In most industries, the majority of polishing operations are completed by the operators manually. The operator's skill is responsible for the surface quality and shape correctness of the polished die. The skilled operators spend a lot time attaining the necessary roughness on the die surface. The die polishing operations consume almost $30 \%$ to $40 \%$ of the overall die manufacturing time. The skilled operators 
usually avoid polishing operations due to poor working environment owing to dust and noise pollution. It is recognized that the manual polished surface appears good, but this operation smears the metal, and the polished surface may contain folded metal instead of parent metal. After a few drawing cycles, the folded metal becomes weak, and gets pulled out by the wire drawing metal, thereby damaging the die [1,2].

Tungsten carbide is generally utilized in wire drawing dies to meet quality, uptime, and speed standards. However, die life shortens due to poor surface finish, leading to early failure of the die. The poor surface finish of the die also leads to die defects such as U-shaped cracks, pitting, wear rings, and vertical and horizontal cracks. In the drawing operation, the wire contacts the die hole repeatedly, loosening the tungsten carbide particles and forming a rough surface. The rough surface scrapes metal pieces of the steel wire's surface, causing the lubrication to weaken and the wear rate to increase [3,4]. Lilly et al. [5] reported, while reviewing the automated finishing of dies, that out of the total time spent on die or mold manufacturing, 37\% to $50 \%$ of time was wasted on polishing the dies. These operations are carried out by expert operators using conventional methods. The automation of this operation becomes difficult due to the high intensity of expertise and ability needed. Moreover, this situation arises due to a shortage of polishing parameter data and surface features, even though little research work has been reported in this field [6]. Therefore, to achieve better productivity and to resolve the probable scarcity of skilled operators, more than a few papers have reported on automated polishing.

The polishing on cold forging dies was completed with expert and non-expert operators, and their skill was measured by checking surface roughness, work time, and the variation from the designated thickness. The authors reported a disparity among expert and non-expert operators in terms of operating time and repetition accuracy. The operator needs several years to become an expert or to be skilled in polishing dies. Kito et al. [7] also investigated the polishing of cold-forged die with a skilled and non-skilled operator, and termed polishing as a removal operation. Tian et al. [8] performed automatic robotic polishing on NAK80 steel mold parts to diminish manual finishing costs and improve quality. The robot-assisted polishing of die and mold were investigated to enhance efficiency, reliability, and robustness $[9,10]$.

Abrasive flow machining (AFM) was recognized as one of the promising technologies for fine finishing of hard and tough surfaces during the early seventies, but Kohut [11] was the first researcher who highlighted the application of AFM to polish extrusion dies, and reported that hand polishing leads to the folding of the metal. The AFM can remove the recast layer produced by EDM and achieve roughness equal to $0.05 \mu \mathrm{m}$ [12]. The experimental work was conducted to comprehend the mechanism of material removal and the wear comportment treated by AFM and magnetically assisted AFM [13] The centrifugal force-assisted AFM was applied to study the effect of shape, rotational speed, extrusion pressure, number of operation cycles, and abrasive grit size. The input variables significantly affect material removal and surface roughness [14]. The AFM can finish complicated shapes and geometries and is ideal for polish operations because dies offer constraints to flowing media; thus, removing the prerequisite of a fixture [15]. Taguchi's experiment methodology was applied to finish conventional machined cylindrical surfaces with AFM [16]. The AFM could easily remove EDM-damaged layers [17]. The AFM set-up was designed and fabricated to the micromachine hole of the nozzle [18]. A mechanism was developed to improve polishing effects on the workpiece surface by designing different passageways. This resulted in the uniform roughness of the circular holes [19]. The AFM process was utilized to enhance a cycloidal pump's outer rotor's surface feature and achieved $0.054 \mu \mathrm{m}$ Ra of tooth top, $0.094 \mu \mathrm{m}$ Ra of the tooth surface, and $0.185 \mu \mathrm{m}$ Ra of tooth root along with $0.4 \mathrm{~g}$ removed material [20]. The surface quality results were achieved successfully by applying AFM to helical gear [21]. A polymer abrasive gel was developed for AFM to polish, and to trim the die of HSS. The achieved results were comparable with commercially available media with higher costs than the developed media [22]. The AFM was applied to finish the stainless-steel knee joint. The AFM operation reduced 
machining time by $76.56 \%$ compared with the ball-end tool utilized to finish the knee joint [23]. The AFM process achieved a surface roughness enhancement of $92.20 \%$, while nano-finishing surgical stainless steel 316L tubes [24,25] optimized AFM parameters viz. abrasive concentration, extrusion pressure, and the number of cycles by the Taguchi method to improve surface finish. The chemical-AFM was designed to polish the interior surfaces of tubular IN625 parts and achieved enhanced texture and surface free form semi-welded particles [26]. The recent advancements in the AFM are described in the context of other media of lower prices, the expansion of tools and fixtures, and ecological matters [27]. Yunus and Alsoufic [28] optimized abrasive flow parameters while machining composite material previously cut with wire EDM. Bhardwaj et al. [29] highlighted that the AFM process has innovative modifications to develop a well-organized practice to achieve a better class product with a superior finish. The technical quality of the steel surface produced by laser and abrasive water jet cutting was evaluated [30]. An abrasive water jet cutting was used to assess the impact of a curve form cut out in a brittle material [31].

TOPSIS is a compensatory aggregation technique comparing a collection of choices by identifying the weight of every characteristic, normalizing and calculating the geometric distance from each choice to the ideal option, which is the best mark for each yardstick. TOPSIS allows trade-offs between criteria: i.e., another criterion's promising outcomes can disallow one disappointing performance. This gives more authentic modelling than noncompensatory approaches that include or exclude hard cut-off choices [32,33]. The TOPSIS technique was utilized to attain optimal solution during ultrasonic-assisted electrochemical magnetic abrasive machining [34]. The TOPSIS method was used in conjunction with entropy weights to achieve optimum energy consumption, surface quality and production rate during the turning process [35]. TOPSIS was used for ordering the experiments the during EDM micro-drilling process [36]. The Taguchi-TOPSIS method has been utilized in electrical discharge machining to enhance machined surface quality and productivity [37]. TOPSIS, in conjunction with the Taguchi method, was successfully applied in machining operations for multi-objective optimization, and TOPSIS is also a well-known technique for ranking alternatives or experiments based on the compensatory aggregation technique [38].

The literature review reveals that abrasive flow machining is a well-established technology for fine finishing intricate profiles and geometries. However, the literature is scant to compare and validate the application of AFP to replace conventional die polishing methods, which are labor-intensive and time-consuming. AFP seems one of the possible methods that can be used for the polishing of dies, as it can promote the product's inner surface quality and economize the labor cost. Hand polishing of carbide dies is performed frequently in industries, but the literature is silent with regard to applying abrasive flow machining to enhance surface roughness and machining time. Polishing a die with free-form surfaces is a time-consuming and onerous task requiring a high level of precision, and great accuracy is needed to keep the requisite size. Several employees have begun to shun polishing work because of the unpleasant working environment created by dust and noise. This method is incapable of achieving the fine polishing required for efficient wire drawing. In addition, the surface finish of the wire drawing die determines the quality of the wire and die life. The hand polishing operation cannot achieve the required surface finish, and it shortens the die life. Therefore, it is necessary to suggest and explore new and advanced methods to polish the die.

So, in the present study, the multi-objective optimization (MOO) of responses such as final surface roughness (F-Ra), percentage improvement of surface roughness (\% age I-Ra), and total polishing time (TPT) was accomplished with the technique of the TaguchiTOPSIS Equal-Weight. Furthermore, the TOPSIS method was also utilized to select the best hand-polished die, and the results were compared with abrasive flow polished die. The performance of AFPed and HPed dies in the context of bearing diameter and percentage reduction in surface roughness was also evaluated in a wire drawing operation that included abrasive flow and hand polishing. 


\section{Materials, Method, and Experimentation}

Tungsten carbide (WC) wire drawing dies were taken as workpieces in the present research. WC had a hardness of 8.5-9 on Moh's scale at 22 GPa, a molar mass of $195.86 \mathrm{~g} / \mathrm{moL}$ with the grey appearance of density $15.8 \mathrm{~g} / \mathrm{cm}^{3}$, a melting point of $2870{ }^{\circ} \mathrm{C}$, a boiling point of $6000{ }^{\circ} \mathrm{C}$. It was also insoluble in water with a hexagonal crystal structure, according to the information provided by the supplier (Fine Spark, Pune, India). An indigenously developed AFP machine in the laboratory (Figure 1) was used to polish the WC dies. The abrasive media was prepared by mixing boron carbide abrasives with silicon-based polymer and hydrocarbon gel. Whereas the polymer provided necessary stiffness to the media, the gel facilitated the media's smooth movement through the workpiece cavity.

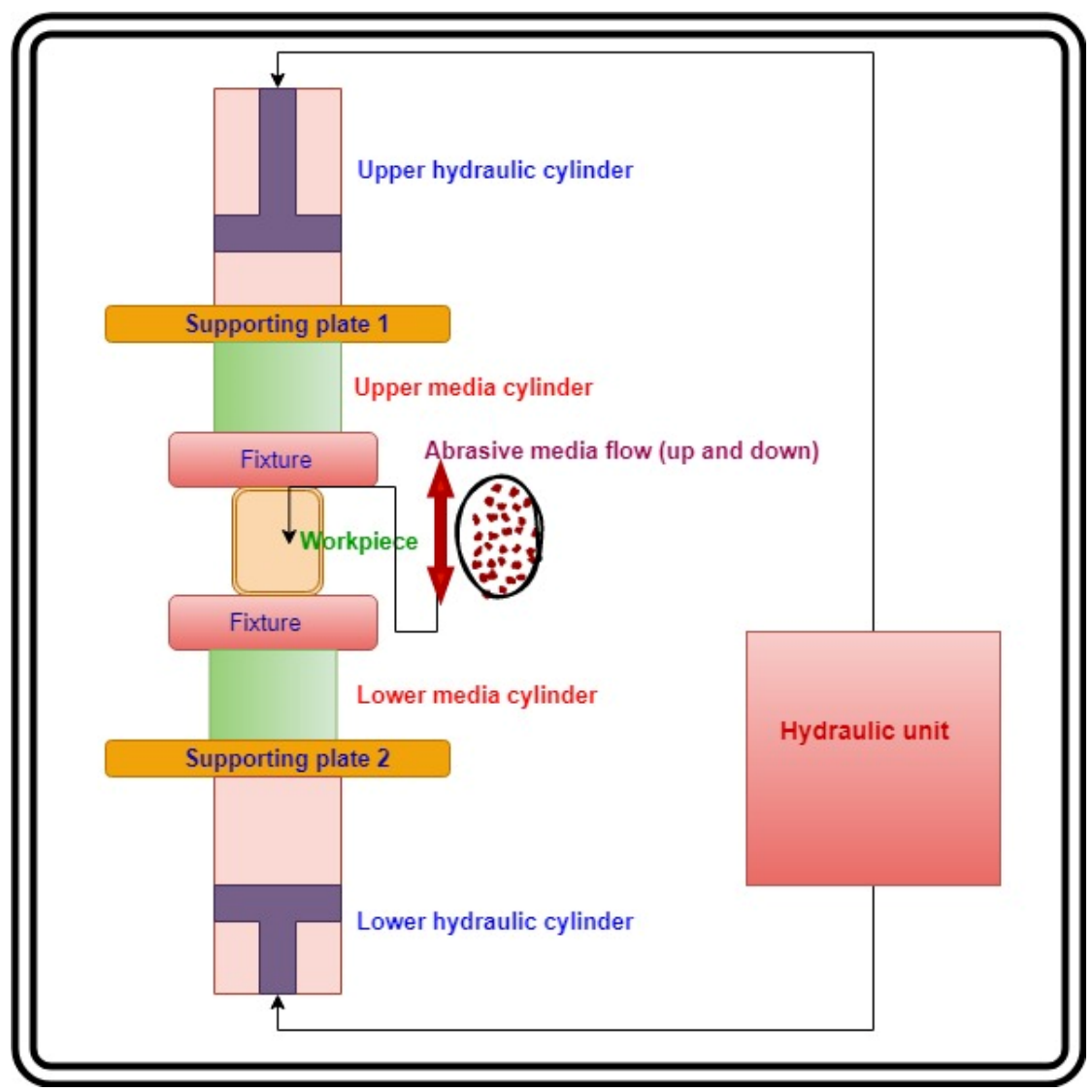

Figure 1. Abrasive flow machining set-up.

\subsection{Experimental Set-Up 1: Abrasive Flow Polishing}

Figure 1 describes the working parts of the abrasive flow polishing machine. Figure 1 illustrates the functional features of the AFP machine set-up. It is prepared by arranging various hydraulic system components according to their functions. The lower media cylinder was packed with abrasive media while maintaining the piston and upper hydraulic cylinder at the apex point. The workpiece (die) was put in a fixture place. The fixture directed the media from the lower cylinder to the upper cylinder through the die. The powerpack or hydraulic unit generated hydraulic pressure in the die passage, as the die diameter was relatively smaller than the diameter of the media cylinders. Due to the constriction in media flow, the extrusion pressure was generated, as indicated on the pressure gauge. The movement of media from the lower cylinder to the upper cylinder and then back to the lower cylinder was termed as a cycle. A couple of cycles were needed to create a fine finish on the die passage.

The effects of three prominent parameters of AFP viz. extrusion pressure (Ep), number of cycles, and abrasive concentration (Ac) on the performance characteristics, such as surface roughness $(\mathrm{Ra})$, percentage improvement of $\mathrm{Ra}$, and polishing time, have been 
studied. The parameters were decided as per the trial of experiments and literature review [39]. The levels of variables are shown in Table 1. The experimental trials were conducted as per standard Taguchi L9 orthogonal array [40]. Experiments were designed and statistically analyzed with Minitab 16 software. The performance characteristics were recorded against various trials, and are shown in Table 2.

Table 1. Abrasive flow polishing variables.

\begin{tabular}{ccccc}
\hline Sr. No. & Variables & $\mathbf{1}$ & Levels & $\mathbf{2}$ \\
\hline A & Extrusion Pressure (Ep), Bar & 65 & 85 & 105 \\
B & Number of Cycles (Noc) & 80 & 130 & 180 \\
C & Abrasive Concentration & 50 & 55 & 60 \\
\hline
\end{tabular}

Table 2. Taguchi L9 orthogonal array, experimental observations.

\begin{tabular}{|c|c|c|c|c|c|c|c|c|}
\hline Exp. No. & $\begin{array}{l}\text { Extrusion } \\
\text { Pressure } \\
\text { (Ep), Bar }\end{array}$ & $\begin{array}{c}\text { Number of } \\
\text { Cycles } \\
\text { (Noc) }\end{array}$ & $\begin{array}{c}\text { Abrasive } \\
\text { Concentration } \\
\text { (Ac), } \%\end{array}$ & $\begin{array}{l}\text { I-Ra } \\
(\mu \mathrm{m})\end{array}$ & $\begin{array}{l}\text { F-Ra } \\
(\mu \mathrm{m})\end{array}$ & $\begin{array}{c}\text { Percentage } \\
\text { I-Ra }\end{array}$ & $\begin{array}{c}\text { PT } \\
\text { One Cycle } \\
\text { (s) }\end{array}$ & $\begin{array}{r}\text { TPT } \\
\text { (min) }\end{array}$ \\
\hline 1 & 65 & 80 & 50 & 2.612 & 1.708 & 34.61 & 24 & 32 \\
\hline 2 & 65 & 130 & 55 & 2.834 & 1.498 & 47.14 & 24 & 52 \\
\hline 3 & 65 & 180 & 60 & 2.792 & 1.439 & 48.46 & 24 & 72 \\
\hline 4 & 85 & 80 & 55 & 2.871 & 1.231 & 57.12 & 11 & 15 \\
\hline 5 & 85 & 130 & 60 & 2.549 & 1.019 & 60.02 & 11 & 24 \\
\hline 6 & 85 & 180 & 50 & 2.783 & 0.942 & 66.15 & 11 & 33 \\
\hline 7 & 105 & 80 & 60 & 2.634 & 0.879 & 66.63 & 7 & 9 \\
\hline 8 & 105 & 130 & 50 & 2.456 & 0.721 & 70.64 & 7 & 15 \\
\hline 9 & 105 & 180 & 55 & 2.694 & 0.549 & 79.62 & 7 & 21 \\
\hline
\end{tabular}

I-Ra: initial surface roughness, F-Ra: final surface roughness, \% age I-Ra: percentage improvement of surface roughness, PT: polishing time, TPT: total polishing time.

\subsection{Experimental Set-Up 2: Hand Polishing}

The pictorial view of the special-purpose machine for the hand polishing (HP) of WC wire drawing dies is shown in Figure 2. It consists of a grinding machine, a three-jaw chuck is fastened in place of the grinding wheel to grip the die, and it is rotated at 2800 RPM.

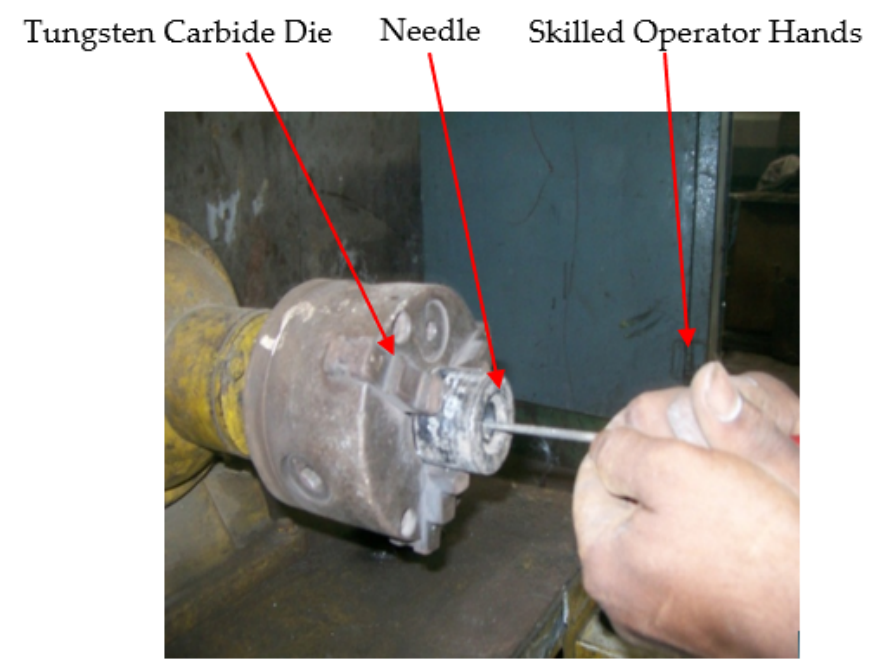

Figure 2. Hand polishing of die by the skilled operator.

The high carbon needle is used to confer the desired die angle, and a wooden needle is utilized to polish the die surface. The needle is smeared with the paste of boron carbide 
40 and then used for polishing the die. The chuck holds the die and is rotated while the polishing needle is inserted inside the die. The skilled operator performs the HP operation. After completing the HP operation, the diameter measurement was performed with a small hole gauge, then the size of the small hole gauge was measured with the micrometer. All the observations were repeated three times, and mean values were considered for further analysis.

\subsection{Experimental Set-Up 3: Wire Drawing Operation}

The wire drawing machine at Ball Kings Industry, Focal point, Ludhiana, Punjab, India, was used to check the performance of HPed, and AFPed WC dies. Table 3 shows the standard conditions for the continuous wire drawing set-up. The wire drawing operation consists of various processes, and the layout of the procedure is shown in Figure 3. The payoff process involves a stand onto which a wire bundle is mounted, and the wire is fed to the machines. When the wire rod's physical impurities are removed, such as scale, oil, grease, etc., for cleaning the material for the further drawing and coating processes, this is called Pickling. The acid used for brushing was sulphuric acid maintained at $40-60{ }^{\circ} \mathrm{C}$ and 15-20\% concentration.

Table 3. Standard multi-stage wire drawing operation.

\begin{tabular}{cccccccc}
\hline No. of Stages & 1st & 2nd & 3rd & 4th & 5th & 6th & 7th \\
\hline The diameter of the drum (mm) & 600 & 595 & 590 & 590 & 585 & 585 & 585 \\
Finishing speed (RPM) & 21 & 24 & 33 & 42 & 56 & 61 & 70 \\
Die material & \multicolumn{7}{c}{ Tungsten Carbide } \\
Material to be drawn & 5.5 & 5.05 & 4.63 & 4.23 & 3.85 & 3.5 & 3.2 \\
Inlet wire size (mm) & 5.05 & 4.63 & 4.23 & 3.85 & 3.5 & 3.2 & 2.92 \\
Finished wire size (mm) & 8.18 & 8.31 & 8.63 & 8.9 & 9.09 & 8.5 & 8.75 \\
\% age reduction &
\end{tabular}

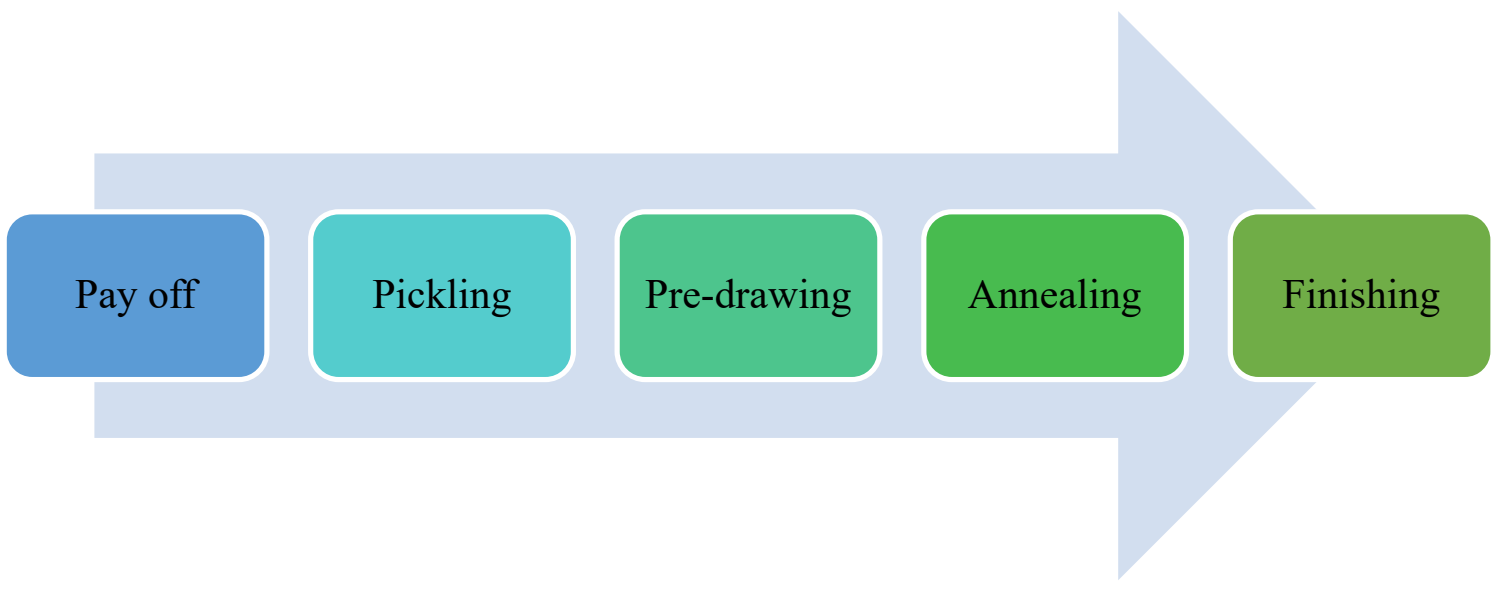

Figure 3. Wire drawing operation layout.

Furthermore, the wire was immersed in a borax tank, providing a thin film on the surface of the wire, which helps protect the die and increase its life. Then, the pre-drawing and annealing were performed. The last step was finishing, and at this stage hand and AFP polished tungsten carbide dies were utilized one by one. The performance was checked at three stages of the wire drawing process. Finally, the same quantity of 5 Tons of EN9 wire material was processed or drawn from both the dies, i.e., hand and AFP polished and all set of experiments were repeated three times.

\subsubsection{Roughness Tester}

The surface roughness tester SJ-301 (Mitutoyo, Michigan, America) with a standard detector of $10 \mu \mathrm{m}$, a tip radius of $5 \mu \mathrm{m}$ (diamond stylus), and a $0.4 \mu \mathrm{m}$ resolution with a 
sample length of $8 \mathrm{~mm}$ was utilized to assess surface roughness ( $\mathrm{Ra})$. It was evaluated with a differential inductance detecting technique at five different locations picked arbitrarily, and the average value was considered for further evaluation [41], with reference to a DIN EN ISO 4288 [42]. The surface roughness of abrasive flow and the hand-polished die was measured randomly from three places, and at each selected location, three readings were completed. An average of all observations were used for further analysis. In addition, a stopwatch was used to note the polishing time.

\subsubsection{Scanning Electron Microscopy}

Surface morphological observations were conducted on the AFP and hand-polished dies by scanning electron microscope apparatus (SEM, Carl Zeiss, Bangalore, India) at an accelerating voltage of $15 \mathrm{kV}$.

\section{Results and Discussion}

\subsection{Multi-Objective Optimization (MOO)}

In the current research, the "Technique for Order Preference by Similarity to Ideal Solution" (TOPSIS) method was used to perform MOO and to select the best hand-polished die [43]. The multiple composite scores (MCS) were calculated and optimized, utilizing the "Taguchi method" to attain the optimum variables [44-46]. The MOO includes selecting the study's objectives and preparing the decision matrix (TDM), as per Equation (1) [35,47]. Every row was assigned to one experiment, and every column had one response (F-Ra, \% age I-Ra, TPT, etc.).

$$
\mathrm{TDM}=\left[\begin{array}{cccccc}
\mathrm{e}_{11} & \mathrm{e}_{12} & -- & \mathrm{e}_{1 \mathrm{j}} & -- & \mathrm{e}_{1 \mathrm{~m}} \\
\mathrm{e}_{21} & \mathrm{e}_{22} & -- & \mathrm{e}_{2 j} & -- & \mathrm{e}_{2 \mathrm{~m}} \\
-- & -- & -- & -- & -- & -- \\
\mathrm{e}_{\mathrm{i} 1} & \mathrm{e}_{\mathrm{i} 2} & -- & \mathrm{e}_{\mathrm{ij}} & -- & \mathrm{e}_{\mathrm{im}} \\
-- & -- & -- & -- & -- & -- \\
\mathrm{e}_{\mathrm{n} 1} & \mathrm{e}_{\mathrm{n} 2} & -- & \mathrm{e}_{\mathrm{nj}} & -- & \mathrm{e}_{\mathrm{nm}}
\end{array}\right]
$$

Normalization of decision matrix $\left(\mathrm{NDM}_{\mathrm{ij}}\right)$ was completed by Equation (2) and the weighted normalized matrix $\left(\mathrm{WH}_{\mathrm{ij}}\right)$ by Equation (3) $[35,47]$. In the current study, the numbers of responses in the AFP were three (3); therefore, the weight $\left(w_{j}\right)$ assigned to each individual response was $33.33 \%$.

$$
\begin{gathered}
\operatorname{NDM}_{i j}=\left[\frac{e_{i j}}{\left[\sum_{i=1}^{n} e_{i j}^{2}\right]^{\frac{1}{2}}}\right](\text { for } j=1,2, \ldots m) \\
W_{i j}=\left[w_{j} \times N_{i j}\right]
\end{gathered}
$$

The ideal best $\left(\mathrm{H}^{+}\right)$and ideal worst $\left(\mathrm{H}^{-}\right)$solutions were attained by Equation (4) and Equation (5), respectively [35,47-49]. $\mathrm{H}^{+}$and $\mathrm{H}^{-}$solutions were the utmost and least value among all response values, respectively:

$$
\begin{gathered}
\mathrm{H}_{\mathrm{j}}^{+}=\left\{\operatorname{best}\left(\mathrm{H}_{\mathrm{ij}}\right)\right\}_{\mathrm{i}=1}^{\mathrm{n}} \mathrm{H}^{+}=\left\{\mathrm{H}_{1}^{+}, \mathrm{H}_{2}^{+}, \ldots, \mathrm{H}_{\mathrm{j}}^{+}, \ldots \mathrm{H}_{\mathrm{m}}^{+}\right\} \\
\mathrm{H}_{\mathrm{j}^{\prime}}^{-}=\left\{\operatorname{worst}\left(\mathrm{H}_{\mathrm{ij}^{\prime}}\right)\right\}_{\mathrm{i}=1}^{\mathrm{n}} \mathrm{H}^{-}=\left\{\mathrm{H}_{1}^{-}, \mathrm{H}_{2}^{-}, \ldots, \mathrm{H}_{\mathrm{j}^{\prime}}^{-}, \ldots \mathrm{H}_{\mathrm{m}^{\prime}}^{-}\right\}
\end{gathered}
$$

where $\mathrm{j}$ and $\mathrm{j}^{\prime}$ are concerned with the beneficial $(\mathrm{m})$ and non-beneficial attributes $\left(\mathrm{m}^{\prime}\right)$, respectively, and formulate separation measures (Sep) with the help of Euclidean distance, as given in Equations (6) and (7) [35,47]. Then, the multiple composite scores (MCS) of all alternatives (experiments) were calculated by Equation (8), and further optimized by the 
"Taguchi method" to complete MOO [50,51], or to pick the best alternative. MCS is laid in descending order [52].

$$
\begin{gathered}
\operatorname{Sep}_{i}^{+}=\left\{\sum_{j=1}^{m}\left(\mathrm{H}_{\mathrm{ij}}-\mathrm{H}_{\mathrm{j}}^{+}\right)^{2}\right\}^{0.5} \\
\operatorname{Sep}_{\mathrm{i}}^{-}=\left\{\sum_{\mathrm{j}^{\prime}=1}^{\mathrm{m}^{\prime}}\left(\mathrm{H}_{\mathrm{ij}}-\mathrm{H}_{\mathrm{j}^{\prime}}^{-}\right)^{2}\right\}^{0.5} \\
\operatorname{MCS}=\frac{\operatorname{Sep}_{\mathrm{i}}^{-}}{\operatorname{Sep}_{\mathrm{i}}^{+}+\operatorname{Sep}_{\mathrm{i}}^{-}}
\end{gathered}
$$

\subsection{Application of Multi-Objective Optimization to Abrasive Flow Polishing}

Table 4 depicts the response decision matrix of AFP used for optimization as per Equation (1). The normalized decision matrix of AFP was calculated as per Equation (2) and is presented in Table 4 . The \% age I-Ra has a "the higher, the better"-type response, and the F-Ra and TPT are "the lower, the better"-type responses. The calculation was assumed to be up to four significant decimal places. The weights for responses of AFP were assumed to have equal importance, and came out to be $33 \%$ due to the three responses. The weighted, normalized AFP matrix obtained by Equation (3) is also presented in Table 4. The positive ideal (best) solution was estimated by Equation (4) and the negative ideal (worst) solution by Equation (5), and the obtained results for AFP were F-Ra $(0.0522,0.1626)$, TPT $(0.0279,0.2233)$ and percentage I-Ra $(0.1466,0.0637)$.

Table 4. Decision matrix of abrasive flow polishing responses.

\begin{tabular}{ccccccccc}
\hline Exp. & \multicolumn{3}{c}{ Decision Matrix } & \multicolumn{2}{c}{ Normalized Decision Matrix } & \multicolumn{2}{c}{ Weighted, Normalized Matrix } \\
No. & F-Ra & TPT & \% Age I-Ra & F-Ra & TPT & \% Age I-Ra & F-Ra & TPT \\
\% Age I-Ra \\
\hline 1 & 1.708 & 32 & 34.61 & 0.4877 & 0.2978 & 0.1912 & 0.1626 & 0.0993 \\
2 & 1.498 & 52 & 47.14 & 0.4277 & 0.4839 & 0.2604 & 0.1426 & 0.1613 \\
3 & 1.439 & 72 & 48.46 & 0.4109 & 0.6700 & 0.2677 & 0.1370 & 0.2233 \\
4 & 1.231 & 15 & 57.12 & 0.3515 & 0.1396 & 0.3155 & 0.1172 & 0.0465 \\
5 & 1.019 & 24 & 60.02 & 0.2909 & 0.2233 & 0.3315 & 0.0970 & 0.0744 \\
6 & 0.942 & 33 & 66.15 & 0.2690 & 0.3071 & 0.3654 & 0.0897 & 0.1024 \\
7 & 0.879 & 9 & 66.63 & 0.2510 & 0.0837 & 0.3680 & 0.0837 & 0.0279 \\
8 & 0.721 & 15 & 70.64 & 0.2059 & 0.1396 & 0.3902 & 0.0686 & 0.0465 \\
9 & 0.549 & 21 & 79.62 & 0.1567 & 0.1954 & 0.4398 & 0.0522 & 0.0651 \\
\hline
\end{tabular}

Equation (6) was applied to calculate a positive separation solution $\left(\mathrm{Sep}_{\mathrm{i}}{ }^{+}\right)$, and Equation (7) to figure the negative separation solution $\left(\mathrm{Sep}_{\mathrm{i}}{ }^{-}\right)$of the AFP. The evaluated responses are presented in Table 5. In addition, the multiple composite scores MCS were calculated by Equation (8), and are also shown in Table 5, along with their $\mathrm{S} / \mathrm{N}$ ratios.

Table 5. Separation measures, MCS and S/N ratios of abrasive flow polishing.

\begin{tabular}{ccccc}
\hline Exp. No. & Sep $_{\mathbf{i}}{ }^{+}$ & Sep $_{\mathbf{i}}{ }^{-}$ & MCS & S/N Ratio \\
\hline 1 & 0.1553 & 0.1241 & 0.4441 & -7.051 \\
2 & 0.1718 & 0.0652 & 0.2750 & -11.213 \\
3 & 0.2206 & 0.0361 & 0.1408 & -17.030 \\
4 & 0.0792 & 0.1872 & 0.7026 & -3.065 \\
5 & 0.0739 & 0.1693 & 0.6960 & -3.148 \\
6 & 0.0869 & 0.1527 & 0.6373 & -3.914 \\
7 & 0.0395 & 0.2188 & 0.8472 & -1.441 \\
8 & 0.0298 & 0.2109 & 0.8762 & -1.148 \\
9 & 0.0372 & 0.2099 & 0.8494 & -1.418 \\
\hline
\end{tabular}


The main parameter effects for means and $\mathrm{S} / \mathrm{N}$ ratio calculations of AFP MCS are shown in Figure 4. The MCS increased with a rise in the extrusion pressure, and decreased with a decrease in the number of cycles and abrasive particle concentration. Since MCS are a "the larger the better" attribute, from the plots, for the means and S/N ratios in Figure 4, the AFP variables at most favorable MCS are at a higher level of A, lower level of B, and lower level of C. Tables 6 and 7 show the optimized AFP parameters for the MOO process and ANOVA, respectively.

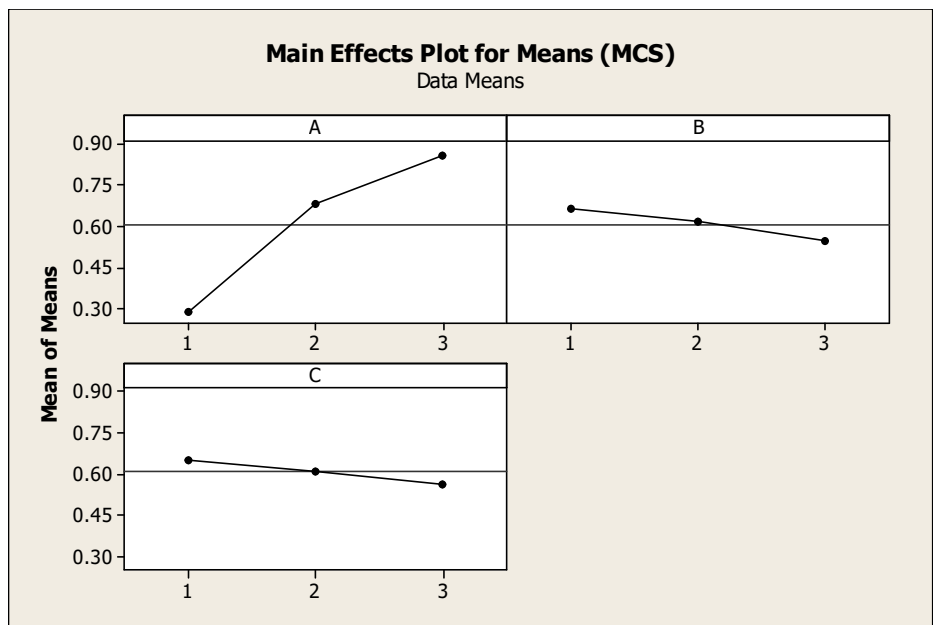

(a)

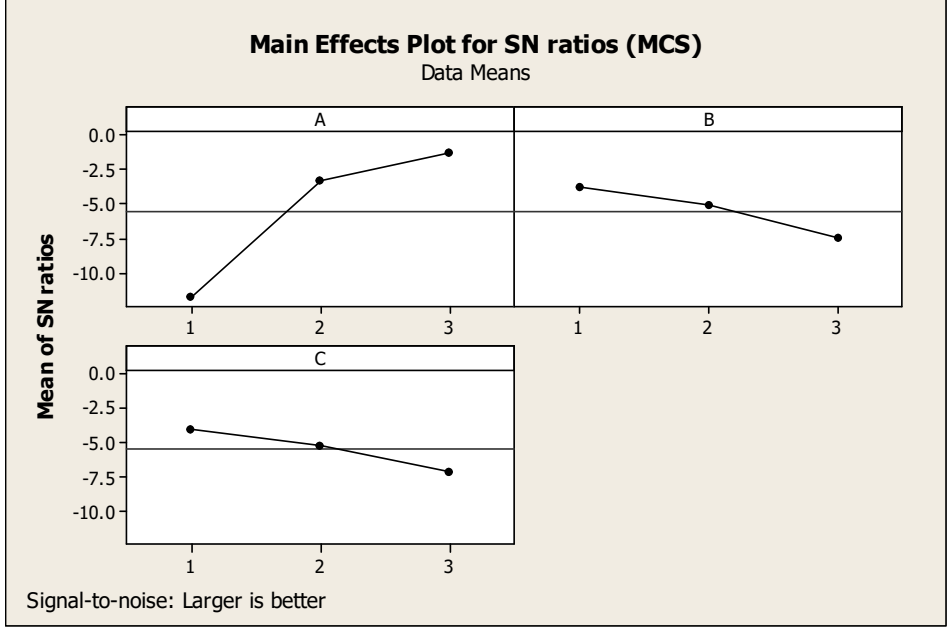

(b)

Figure 4. Main effects plot (a) means of MCS and (b) S/N ratios of MCS.

Table 6. Abrasive flow polishing parameters at optimum MCS and response value.

\begin{tabular}{|c|c|c|c|c|c|c|}
\hline \multirow{2}{*}{\multicolumn{2}{|c|}{$\begin{array}{c}\text { Optimum AFP } \\
\text { (Factor/Level) }\end{array}$}} & \multicolumn{2}{|c|}{ Optimum MCS } & \multirow[b]{2}{*}{ Responses } & \multirow[b]{2}{*}{ Mean } & \multirow{2}{*}{$\begin{array}{l}\text { S/N } \\
\text { Ratio }\end{array}$} \\
\hline & & Mean & $\mathrm{S} / \mathrm{N}$ & & & \\
\hline Ep (A3) & 105 Bar & \multirow{3}{*}{0.9595} & \multirow{3}{*}{-0.3591} & \multirow{2}{*}{$\begin{array}{c}\text { F-Ra }(\mu \mathrm{m}) \\
\text { Percentage } \\
\text { I-Ra }\end{array}$} & 0.887 & 1.0415 \\
\hline Noc (B1) & 80 & & & & 65.12 & 36.2743 \\
\hline $\mathrm{Ac}(\mathrm{C} 1)$ & 50 & & & TPT (min) & 4 & -12.0412 \\
\hline
\end{tabular}


Table 7. ANOVA results in MCS.

\begin{tabular}{ccccccc}
\hline Resource & $\begin{array}{c}\text { Degree of } \\
\text { Freedom }\end{array}$ & $\begin{array}{c}\text { Sum of } \\
\text { Square }\end{array}$ & Variance & $\begin{array}{c}\text { Fisher's } \\
\text { Value }\end{array}$ & Probability & $\begin{array}{c}\text { Contribution } \\
\text { (\%) }\end{array}$ \\
\hline \multicolumn{7}{c}{ MCS means } \\
\hline Ep & 2 & 0.51172 & 0.255859 & 36.18 & 0.027 & 91.21 \\
Noc & 2 & 0.02268 & 0.01134 & 1.6 & 0.384 & 4.04 \\
Ac & 2 & 0.01249 & 0.006245 & 0.88 & 0.531 & 2.23 \\
Residual & 2 & 0.01414 & 0.007072 & & & 2.52 \\
Error & 8 & 0.56103 & & & & 100.00 \\
Total & & & MCS S/N ratios & & \\
\hline & 2 & 183.31 & 91.656 & 11.87 & 0.078 & 78.32 \\
\hline Ep & 2 & 19.93 & 9.963 & 1.29 & 0.437 & 8.52 \\
Noc & 2 & 15.37 & 7.683 & 0.99 & 0.501 & 6.57 \\
Ac & 2 & 15.45 & 7.725 & & & 6.60 \\
Residual & 2 & 234.05 & & & & 100.00 \\
Error & 8 & & & & \\
Total & & & & & & \\
\hline
\end{tabular}

\subsection{Application of TOPSIS Technique to Select the Best Hand-Polished Die}

The best HPed Die was chosen with the TOPSIS technique. Three-hand polishing skilled operators (HP-SO) with different die polishing experiences were considered to polish carbide dies from the industry's available experienced operators. Hand die polishing time depended upon the operator's skill; the skilled operator himself decided the required surface finish of the die and therefore the polishing time depended on this. So, the polishing time was not controllable and was different even when the die was polished by the skilled operator repeatedly. The observations of HP die are tabulated in Table 8 in terms of final surface roughness (HP-F-Ra) in $\mu \mathrm{m}$, hand polishing time (HP-T) in minutes, percentage improvement in surface roughness of HP die (HP-percentage I-Ra), and HP-SO experience in years. Table 8 is also termed as the decision matrix of hand polishing responses as per Equation (1). The percentage HP-I-Ra is a "the higher, the better"-type response, and the HP-F-Ra and HP-T are "the lower, the better"-type responses. The normalized decision matrix of HP responses "NDM ${ }_{\mathrm{ij}}$ " was calculated as per Equation (2) and is presented in Table 8. The weights for HP responses were estimated equally, i.e., $33.33 \%$. The weighted, normalized matrix $\left(\mathrm{WH}_{\mathrm{ij}}\right)$ of $\mathrm{HP}$, obtained by Equation (3), is presented in Table 8 . The positive ideal (best) solution was estimated by Equation (4), and the negative ideal (worst) solution by Equation (5), and the obtained results of HP were HP-F-Ra $(0.0744,0.1414)$, HP-T $(0.0849,0.1289)$ and HP-Percentage I-Ra $(0.1346,0.951)$.

Table 8. Observations and decision matrix of HP responses.

\begin{tabular}{ccccccccccc}
\hline & & \multicolumn{3}{c}{ Decision Matrix } & \multicolumn{2}{c}{ Normalized Matrix } & \multicolumn{2}{c}{ Weighted, Normalized Matrix } \\
\cline { 2 - 9 } Exp. No. & HP-SO & $\begin{array}{c}\text { HP-F-Ra } \\
(\boldsymbol{\mu} \mathbf{m})\end{array}$ & $\begin{array}{c}\text { HP-T } \\
(\mathbf{m i n})\end{array}$ & $\begin{array}{c}\text { HP-\% } \\
\text { Age I-Ra }\end{array}$ & HP-F-Ra & HP-T & $\begin{array}{c}\text { HP-\% } \\
\text { Age I-Ra }\end{array}$ & HP-F-Ra & HP-T & $\begin{array}{c}\text { HP-\% } \\
\text { Age I-Ra }\end{array}$ \\
\hline 1 & 1 & 2.167 & 29 & 48.89 & 0.2231 & 0.2548 & 0.3405 & 0.0744 & 0.0849 & 0.1135 \\
2 & 1 & 2.256 & 32 & 51.25 & 0.2322 & 0.2811 & 0.3569 & 0.0774 & 0.0937 & 0.1190 \\
3 & 1 & 2.743 & 35 & 57.98 & 0.2824 & 0.3075 & 0.4038 & 0.0941 & 0.1025 & 0.1346 \\
4 & 2 & 2.998 & 38 & 48.01 & 0.3086 & 0.3339 & 0.3344 & 0.1029 & 0.1113 & 0.1115 \\
5 & 2 & 3.127 & 40 & 44.93 & 0.3219 & 0.3514 & 0.3129 & 0.1073 & 0.1171 & 0.1043 \\
6 & 2 & 3.258 & 39 & 49.25 & 0.3354 & 0.3426 & 0.3430 & 0.1118 & 0.1142 & 0.1143 \\
7 & 3 & 3.878 & 42 & 40.98 & 0.3992 & 0.3690 & 0.2854 & 0.1331 & 0.1230 & 0.0951 \\
8 & 3 & 3.989 & 40 & 42.58 & 0.4106 & 0.3514 & 0.2966 & 0.1369 & 0.1171 & 0.0989 \\
9 & 3 & 4.091 & 44 & 44.68 & 0.4211 & 0.3866 & 0.3112 & 0.1404 & 0.1289 & 0.1037 \\
\hline
\end{tabular}


Equation (6) was applied to calculate a positive separation solution $\left(\mathrm{Sep}_{\mathrm{i}}{ }^{+}\right)$and Equation (7) to figure the negative separation solution $\left(\mathrm{Sep}_{\mathrm{i}}{ }^{-}\right)$. The evaluated responses of HP are presented in Table 9. The MCS of the HPed die was calculated by Equation (8), also shown in Table 9. The TOPSIS rankings obtained for each experiment of hand-polished die, along with MCS values, are presented in Table 9. Experiment 2 transpired to be the first choice of hand-polished die, followed by Experiment 1.

Table 9. Separation measures and MCS of hand-polished die and TOPSIS ranks.

\begin{tabular}{clllc}
\hline Exp. No. & Sep $_{\mathbf{i}}{ }^{+}$ & Sep $_{\mathbf{i}}{ }^{-}$ & MCS & Rank \\
\hline 1 & 0.0211 & 0.0814 & 0.7941 & 2 \\
2 & 0.0156 & 0.0759 & 0.8294 & 1 \\
3 & 0.0264 & 0.0663 & 0.7148 & 3 \\
4 & 0.0452 & 0.0445 & 0.4962 & 4 \\
5 & 0.0551 & 0.0363 & 0.3968 & 6 \\
6 & 0.0517 & 0.0374 & 0.4200 & 5 \\
7 & 0.0803 & 0.0094 & 0.1044 & 8 \\
9 & 0.0789 & 0.0128 & 0.1394 & 7 \\
\end{tabular}

\section{Comparative Analysis and Confirmation of Results}

The results achieved with the Taguchi-TOPSIS method while utilizing the Equal weight technique were validated with Taguchi-GRA (Grey Relational Analysis) methodology. The optimum parameter achieved by both the methods, i.e., Taguchi-TOPSIS and Taguchi-GRA, was similar. Furthermore, confirmation experiments were performed for the MOO optimal parameters, and mean values were calculated by repeating experiments three times for further analysis. Finally, the Minitab 16 software was used to predict the MCS values. The relative error was used to check the significant difference between experimental and predicted data, as shown in Equation (9). The calculated relative error percentage for MCS is shown in Table 10. The result reveals that the predicted and experimental data were close to each other.

$$
\text { Relative Error Percentage }=\left|\frac{E_{i}-P_{i}}{E_{i}}\right| \times 100
$$

where $E_{i}$ is an experimental value, and $P_{i}$ is the predicted value.

Table 10. Predicted and experimental abrasive flow polished MCS at optimal parameters.

\begin{tabular}{ccccc}
\hline Response & Factor/Level & Predicted & Experimental & Relative Error (\%) \\
\hline MCS & A3, B1, C1 & 0.9595 & 0.9188 & 4.43 \\
\hline
\end{tabular}

\subsection{Comparison between Hand and Abrasive Flow Polished Tungsten Carbide Die}

Furthermore, the best-picked, hand-polished die with the TOPSIS method was compared with the AFP polished die at optimum MOO variables. The percentage changes in AFP responses achieved with $\mathrm{MOO}$ are shown in Table 11. The findings show a noteworthy improvement in responses with AFP polished dies compared to HPed die. The ranks of responses from I to III indicate the order of growth achieved with the MOO. Kenda et al. [53] compared AFP and hand polishing of a hardened steel surface produced by EDM and reported that hand polishing needed twice the time as AFP, with inferior surface quality. 
Table 11. Percentage change in abrasive flow polishing responses in comparison to hand polishing.

\begin{tabular}{cccc}
\hline Responses & $\begin{array}{c}\text { HPed Die } \\
\text { Response Value }\end{array}$ & $\begin{array}{c}\text { AFPed Die } \\
\text { Percentage Change in AFP } \\
\text { Polished Die }\end{array}$ & $\begin{array}{c}\text { Pol } \\
\text { F-Ra }(\mu \mathrm{m})\end{array}$ \\
$\%$ age I-Ra & 51.256 & 0.887 & $-60.68^{\mathrm{II}}$ \\
TPT $(\mathrm{min})$ & 32 & 65.12 & $27.06^{\mathrm{III}}$ \\
\hline
\end{tabular}

I, II, and III are ranks of AFP responses as per improvement; negative sign means improvement for F-Ra and TPT positive sign means improvement for percentage I-Ra.

\subsection{Performance of Hand and Abrasive Flow Polished Die in Three-Stage Wire Drawing}

The performance of the AFP and the hand-polished die was evaluated in the threestage wire drawing operation. The HP-SO 1 was selected per the TOPSIS rank (refer to Table 12) to polish three carbide dies. The die's size was picked as per the size mentioned in Table 3, i.e., standard multi-stage wire drawing operation at Ball Kings, Ludhiana, India. In this research, the dies' performances were evaluated at the third, fourth, and fifth stages of the standard wire drawing operation. In addition, the AFP die polishing parameters were considered (refer to Table 6), obtained with the MOO of the AFP process. The surface deterioration rate may depend upon the initial roughness. However, in the present work, it was ensured that hand-polished and abrasive flow polished dies had almost equal initial surface roughness so that the effect of wire drawing could be noticed without any bias.

Table 12. Observations of three-stage wire drawing operation.

\begin{tabular}{|c|c|c|c|c|c|c|c|}
\hline \multirow{2}{*}{$\begin{array}{l}\text { Polishing } \\
\text { Method }\end{array}$} & \multirow{2}{*}{$\begin{array}{l}\text { Number of } \\
\text { Stages }\end{array}$} & \multicolumn{2}{|c|}{$\begin{array}{c}\text { Surface Roughness, } \\
\operatorname{Ra}(\mu \mathrm{m})\end{array}$} & \multirow{2}{*}{$\begin{array}{c}\text { Percentage } \\
\text { Reduction in } \\
\text { Ra }\end{array}$} & \multicolumn{2}{|c|}{$\begin{array}{l}\text { Bearing Diameter of Die } \\
(\mathrm{mm})\end{array}$} & \multirow{2}{*}{$\begin{array}{c}\text { Increase in Bearing } \\
\text { Diameter of Die } \\
(\mathrm{mm})\end{array}$} \\
\hline & & $\begin{array}{l}\text { Before } \\
\text { Drawing }\end{array}$ & $\begin{array}{c}\text { After } \\
\text { Drawing }\end{array}$ & & $\begin{array}{c}\text { Before } \\
\text { Drawing }\end{array}$ & $\begin{array}{c}\text { After } \\
\text { Drawing }\end{array}$ & \\
\hline \multirow{3}{*}{$\begin{array}{l}\text { Hand } \\
\text { polished }\end{array}$} & First & 2.638 & 3.665 & 38.93 & 4.63 & 4.66 & 0.03 \\
\hline & Second & 2.187 & 3.287 & 50.30 & 4.23 & 4.28 & 0.05 \\
\hline & Third & 2.273 & 3.653 & 60.71 & 3.85 & 3.89 & 0.04 \\
\hline \multirow{3}{*}{$\begin{array}{c}\text { AFP } \\
\text { polished }\end{array}$} & First & 0.798 & 1.013 & 26.94 & 4.63 & 4.65 & 0.02 \\
\hline & Second & 0.854 & 1.221 & 42.97 & 4.23 & 4.27 & 0.04 \\
\hline & Third & 0.831 & 1.259 & 51.50 & 3.85 & 3.89 & 0.03 \\
\hline
\end{tabular}

As shown in Table 12, at the first stage of wire drawing, the percentage of deterioration of Ra with hand-polished die was 38.93, and with the abrasive flow polished die this was 26.94. So, there was $11.93 \%$ more surface decline of hand-polished dies than abrasive flow polished die. In the second stage of wire drawing, the percentage deterioration in surface roughness with HP die was 50.30, and with AFPed die this was 42.97; therefore, there was 7.33\% more surface decline of HPed die compared with AFPed die. Finally, in the third stage of wire drawing, the percentage deterioration in Ra with HPed die was 60.71\%, and with AFPed die this was 51.50. So, there was 9.21\% more surface decline of HPed dies as compared with AFPed die. Accordingly, at each stage, i.e., first, second and third, the bearing diameter of the HPed die enlarged by $25 \%$ compared with the AFPed die.

There was a reduced amount of wear and tear of the abrasive flow polished die compared with the hand-polished die. The magnified view of SEM of the abrasive flow polished die in Figure 5a shows that all surfaces were polished uniformly; the polished surface was parallel to the wire to be drawn. Figure 5a also indicates the surface debris and surface defects. In the hand polishing of die, although the surface looked good, the surface deterioration was greater than that of abrasive flow polished die. Much of the surface is folded metal and not parent metal, so the drawing wire pulls out the folded metal after a short period of use, or dislodges the upper surface of the die [2]. This results in several defects due to the poor surface finish of the die, such as U-shaped cracks, pitting, wear rings, and vertical and horizontal cracks. The wire continually contacts the die hole 
during the drawing process, releasing the tungsten carbide particles and generating a rough surface. The rough surface scrapes metal bits off the surface of the steel wire, weakening the lubrication and increasing the wear rate $[3,4]$.

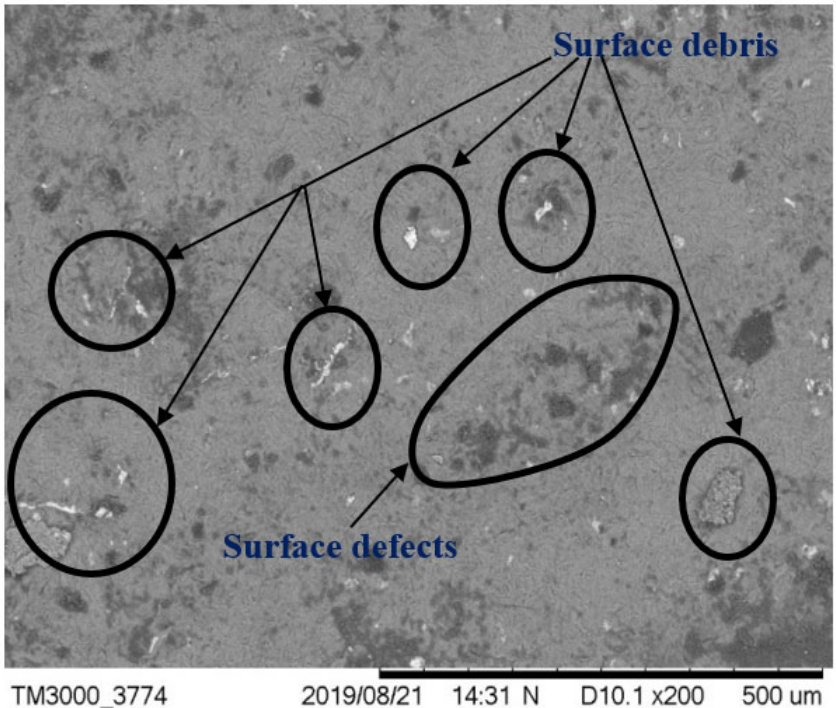

(a)

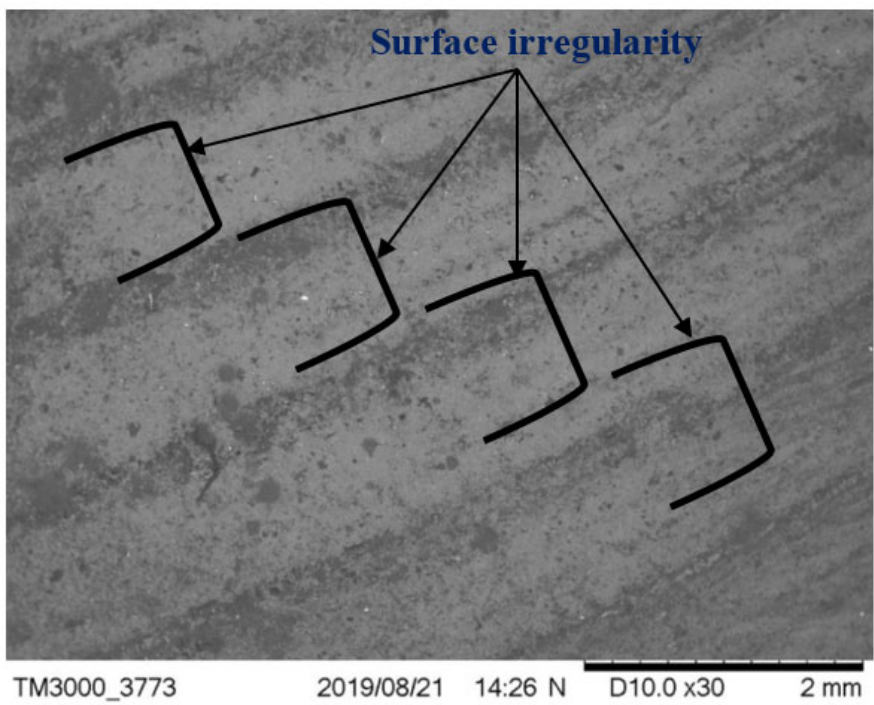

(b)

Figure 5. SEM micrograph of (a) abrasive flow polished die (b) hand polished die.

Figure $5 \mathrm{~b}$ also indicates that the surface is not very uniform. There is no particular lay to the finish. Therefore, some areas could cause more friction than others, possibly resulting in uneven wire flow and further deterioration occurring. Other reasons may be that when the wire initially touches the dies, the tungsten carbide grains are torn out, scratching the die surface. If the surface is rough, there are more chances of tearing out of grains. Abrasive wear results in the bearing and cone area of the die, and this wear may be due to lubricant impurities and the presence of oxide elements on the wire [54].

\subsection{Contour Plots of Abrasive Flow Polished Die}

The effects of AFP variables' extrusion pressure (A), the number of cycles (B), and abrasive concentration (C) on the individual responses' final surface roughness, percentage improvement in surface roughness, and total polishing time can be seen from the contour plots in Figures 6-8, respectively. Minitab 16 software was utilized to draw contour plots. 

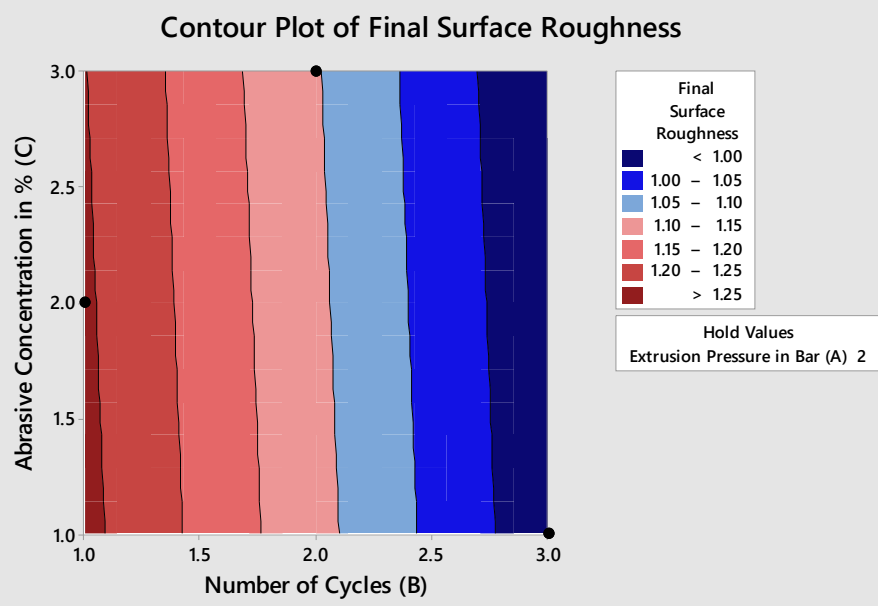

(a)

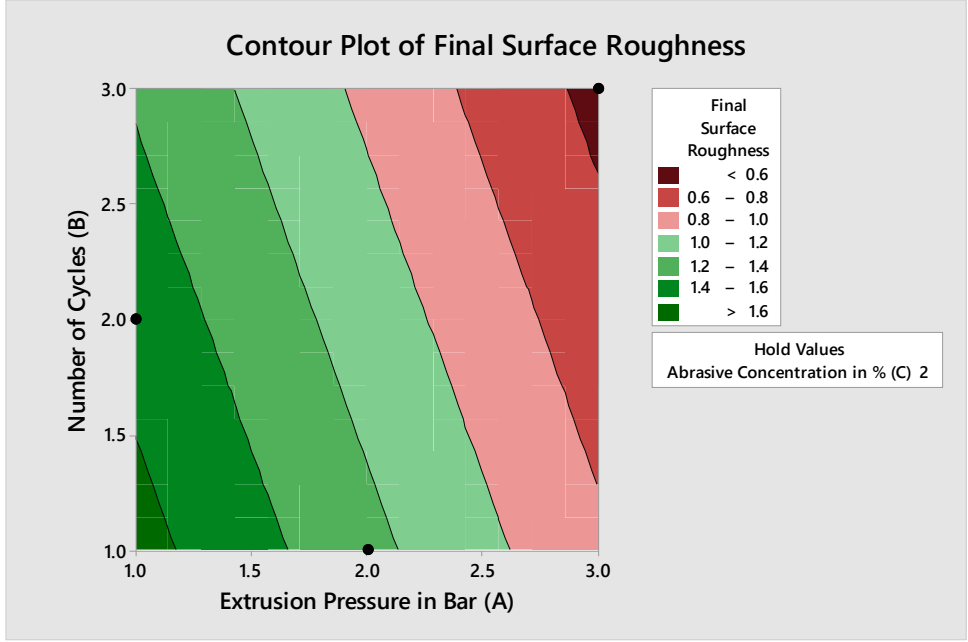

(b)

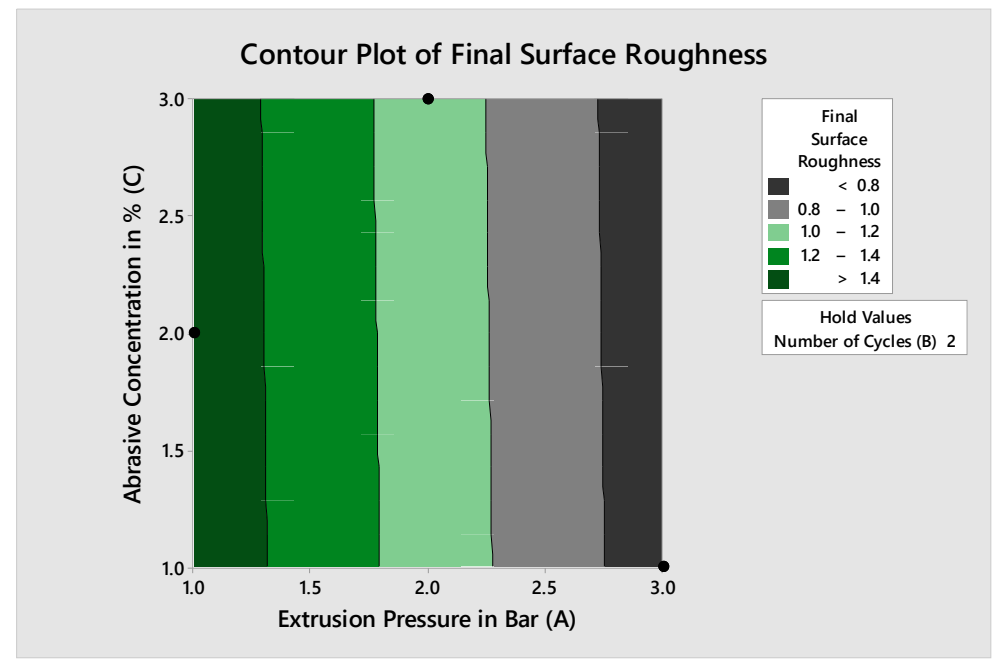

(c)

Figure 6. Contour plots for final surface roughness: (a) plot between abrasive concentration and the number of cycles; (b) plot between the number of cycles and extrusion pressure; (c) plot between abrasive concentration and extrusion pressure. 


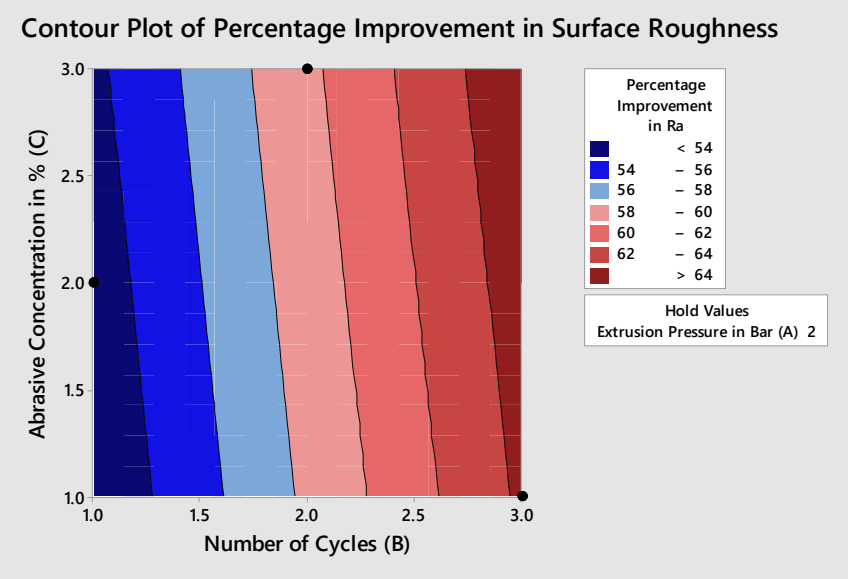

(a)

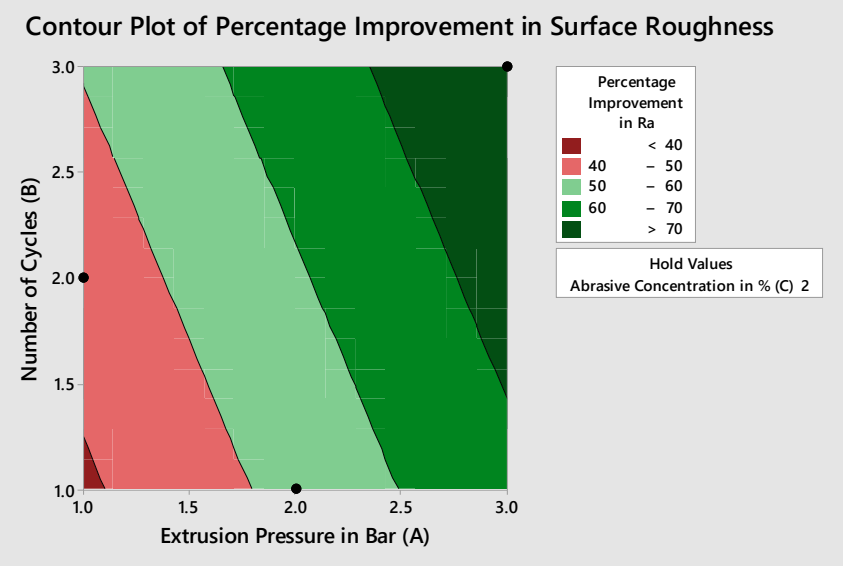

(b)

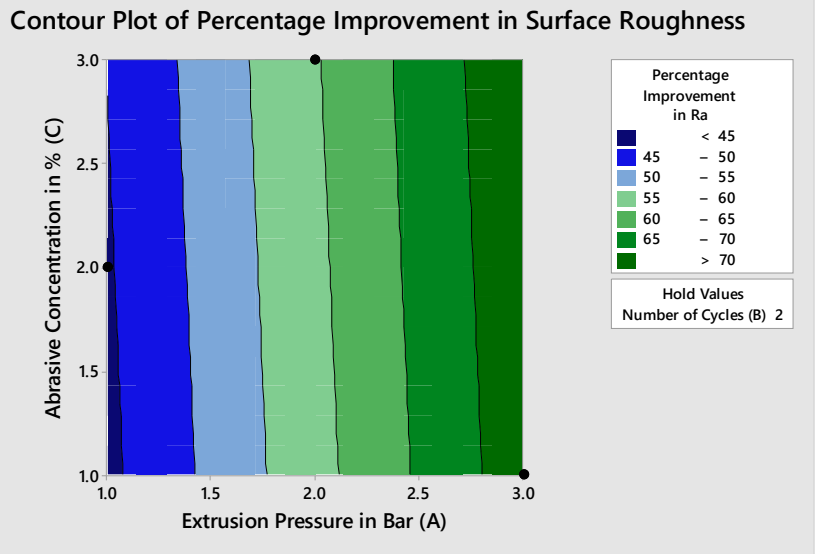

(c)

Figure 7. Contour plots for percentage improvement in surface roughness: (a) plot between abrasive concentration and the number of cycles; (b) plot between the number of cycles and extrusion pressure; (c) plot between abrasive concentration and extrusion pressure.

In Figure 6a, the minimum value of the response final $\mathrm{Ra}$ is characterized by a dark red color. The contour plots are drawn for the linear model of the response at a $95 \%$ confidence level. The contour line encircling this area gives the value of Ra as less than $1 \mu \mathrm{m}$. The number of cycles (B) are plotted on x-axes and abrasive concentration (C) on the y-axes. In Figure $6 \mathrm{~b}$, the minimum value of the response final $\mathrm{Ra}$ is characterized by a dark red color. The extrusion pressure (A) is plotted on x-axes and the number of cycles (B) are plotted on the $y$-axes. The Ra lies around 0.603 to $0.609 \mu \mathrm{m}$, and $B^{*} A$ varies between levels 
$(2.862,2.962)$ to $(2.268,2271)$. Thus, the extrusion pressure has a substantial role in reducing final $\mathrm{Ra}$, and has a significant effect. For the rest of the contour graphs, the area representing the minimum final $\mathrm{Ra}$ is negligible, as in Figure $6 \mathrm{c}$. Therefore, their explanation was not considered, and they had no significant effect on $C^{*} A$ and $C^{*} B$.

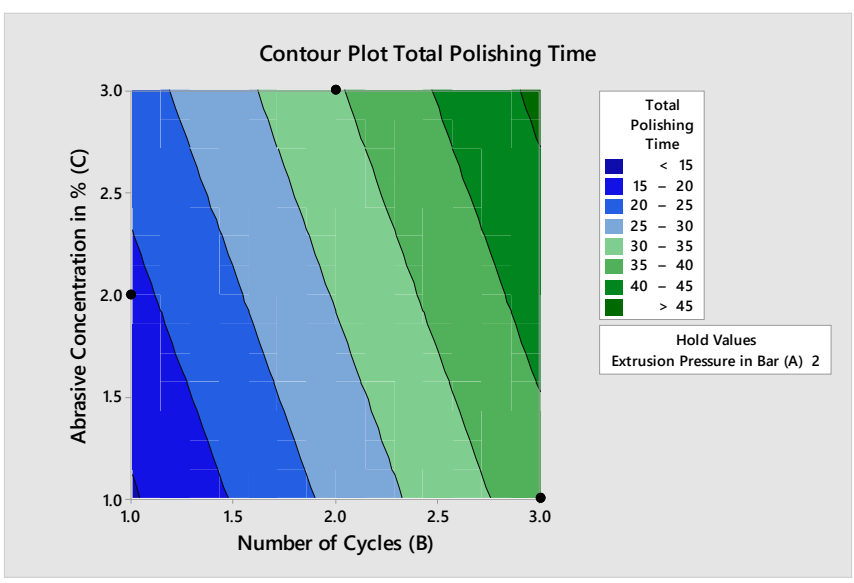

(a)

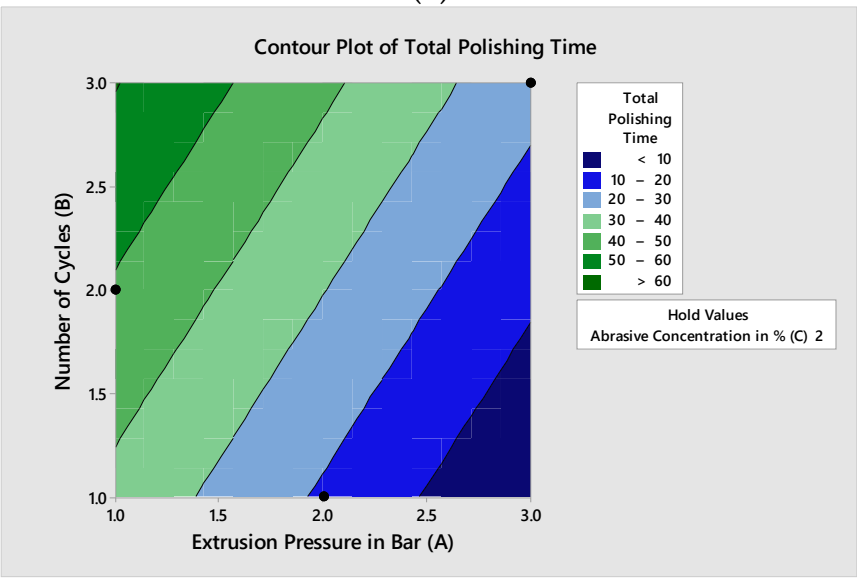

(b)



(c)

Figure 8. Contour plots for total polishing time: (a) plot between abrasive concentration and a number of cycles; (b) plot between the number of cycles and extrusion pressure; (c) plot between abrasive concentration and extrusion pressure.

Similarly, the contour plot for percentage improvement in $\mathrm{Ra}$ is shown in Figure 7, and the dark red color indicates the maximum percentage improvement in the Ra area where optimal variable blend lies. The dark blue color can be seen in the contour plot between 
$\mathrm{B}^{*} \mathrm{~A}(2.365,2.386)$ and $(2.298,1.486)$, with a percentage improvement in Ra from 70 to 70.11 (refer to Figure $7 \mathrm{~b})$. For the $\mathrm{C}^{*} \mathrm{~A}(2.724,2.793)$ to $(2.81,1.02)$ with percentage improvement in $\mathrm{Ra}$ of more than $70 \%$, refer to Figure $7 \mathrm{~b}$. In Figure $7 \mathrm{c}$, for $\mathrm{C}^{*} \mathrm{~B}$, the contour area without the dark blue color shows a non-significant effect on the percentage improvement in Ra.

Similarly, the contour plot for total polishing time is shown in Figure 7, and the dark blue color indicates the minimum total polishing time area where the optimal variable blend lies, and the TPT value is less than 10. The dark blue color can be seen in the contour plot between $\mathrm{B}^{*} \mathrm{~A}(2.988,1798)$ and $(2.471,1.021)$, with TPT less than $10 \mathrm{~min}$. The $\mathrm{C}^{*} \mathrm{~A}$ was $(2.995,1.501)$ to $(2.866,1.121)$. For $C^{*} B$, the contour area without the dark blue color shows a non-significant effect on TPT. The coded variables and their actual values can be seen in Table 1. The extrusion pressure varies from 65 Bar to 105 Bar, the number of cycles from 80 to 180 , and abrasive particle concentration from $50 \%$ to $60 \%$.

As the number of cycles increases, the percentage of improvement in the surface finish also increases. With an increase in the number of cycles, the number of times the abrasives come into contact with the workpiece increases, so the percentage improvement in surface finish increases, and there is a greater percentage improvement in the surface finish in the initial working cycles-after that, the percentage improvement in the surface finish was lesser. This is because a major part of the initial roughness of the workpiece is removed in a few cycles at the beginning of AFM [16]. It is evident that as the pressure increases, the percentage improvement in the surface finish also increases. When the pressure increases, the normal force acting on each grain increases, resulting in a deeper indentation on the workpiece surface. If the axial force on an abrasive is more than the resistance offered by the workpiece material, removing the peaks over the surface of the workpiece takes place, leading to an improved surface finish [14]. At higher pressure, fewer cycles are required to attain a particular surface finish value than low pressure. At low pressure, the indentation force exerted on the workpiece surface is low, which results in a low finishing rate. At high extrusion pressure, the time required to finish a component is reduced because the medium provides greater and deeper indentations on the surface of the workpiece. As the number of cycles increases, the polishing time also increases. With increased extrusion pressure, media flow speed increases and polishing time decreases [28]. With an increase in extrusion pressure, polishing time decreases.

In the present research, the effect of three abrasive flow polishing parameters was studied in terms of final surface roughness, polishing time, and improvement in surface finish. Other abrasive flow polishing parameters, such as type of media and media flow rate, can be considered for future research as the parameters decided in the present case were as per machine set-up constraints. In the present case, abrasive flow polished die performance was compared with hand polishing, and is taken as a case study. Still, there are more polishing techniques utilized in die polishing, such as robotic polishing [10], ultrasonic polishing [55], and computer-controlled polishing processes [56]. Still, some advanced variants of abrasive flow machining have been developed, and work can further be analyzed, such as magneto abrasive flow machining [57], and the recent trends in abrasive flow machining presented in [58].

\section{Conclusions}

In the present research work, polishing of tungsten carbide (WC) wire drawing die has been explored with abrasive flow polishing (AFP) to compare its performance with conventional hand polishing (HP). The Taguchi-TOPSIS Equal-Weight technique was used to achieve multi-objective optimization of final surface roughness (F-Ra), percentage improvement of surface roughness (percentage I-Ra), and total polishing time (TPT). Additionally, the TOPSIS approach was used to identify the best hand-polished die. The applied abrasive flow polishing technique uniquely contributes to the die polishing industry, where dependence on skilled operators can be reduced with the proposed methodology. Furthermore, the proposed method applied to the die polishing process, while considering multiple responses for hand and abrasive flow polishing, has a unique advantage as it can reduce 
the polishing time and enhance the surface quality of the wire drawing die. As a result, it also achieved better results when the performance of the abrasive flow polished die was checked in a multi-stage wire drawing operation. Based on experimental observations and statistical analysis of the results, the following conclusions have been drawn:

- $\quad$ AFPed and HPed die performance in multi-stage wire drawing operation revealed that abrasive flow processing provides better surface quality than hand polishing in terms of wear rate. There were $11.93 \%, 7.33 \%$, and $9.21 \%$ lower wear and tear of AFP surfaces than hand-polished surfaces, at the first, second and third stages of wire drawing operation;

- $\quad$ The bearing diameter of HPed dies enlarged by $25 \%$ more than the AFPed dies. As a result, the AFP offered better surface quality $(\mathrm{Ra})$ in contrast to hand polishing. AFP can reduce the dependency on expensive and increasingly difficult-to-find die finishers or skilled operators. In addition, the AFP polishes all surfaces uniformly within a reasonable amount of time, i.e., a percentage time saving of 87.50 ;

- It was found from the means, S/N plots, and ANOVA analysis (at 95\% confidence level) of AFP that the extrusion pressure had the maximum significance on the MCS calculations with a contribution of $91.21 \%$. In contrast, abrasive particle concentration was seen to be influenced significantly less;

- The multi-objective optimization was performed with the technique of the TaguchiTOPSIS-Equal-Weight. The AFP results were: polishing parameters at extrusion pressure of 105 bars, number of cycles, 80, and an abrasive particle concentration of $50 \%$. There was an improvement of $87.50 \%$ in TPT, $60.68 \%$ in F-Ra, and $27.06 \%$ in percentage I-Ra compared with the best hand-polished die selected with the TOPSIS method;

- $\quad$ The results of the TOPSIS method to pick the best hand-polished die revealed that the skilled operator, having five years of experience, came out to be the first choice, having HP-F-Ra 2.256 $\mu \mathrm{m}, \mathrm{HP}-\mathrm{T}$ of $32 \mathrm{~min}$., and HP-\% age I-Ra of 51.25. This was followed by the same skilled operator, having HP-F-Ra $2.167 \mu \mathrm{m}$, HP-T of $28 \mathrm{~min}$., and HP-\% age I-Ra of 48.89 .

Author Contributions: Conceptualization, R.K., S.S. (Sehijpal Singh) and V.A.; methodology, R.K., S.S. (Sehijpal Singh), S.S. (Sunpreet Singh), D.Y.P. and K.G.; software, K.N., V.A., K.G., R.K. and S.S. (Sehijpal Singh); validation, R.K., K.G., S.S. (Sunpreet Singh), D.Y.P. and V.A.; formal analysis, R.K., K.G. and S.S. (Sehijpal Singh); investigation, D.Y.P., K.G., K.N., V.A. and R.K.; resources, R.K.; data curation, R.K., S.S. (Sehijpal Singh) and V.A.; writing-original draft preparation, R.K.; writing-review and editing, S.S. (Sehijpal Singh), R.K., K.G. and D.Y.P.; visualization, R.K.; supervision, S.S. (Sehijpal Singh), V.A. and S.S. (Sunpreet Singh); project administration, R.K.; funding acquisition, R.K. All authors have read and agreed to the published version of the manuscript.

Funding: Authors did not receive any specific funding for this research.

Institutional Review Board Statement: Not applicable.

Informed Consent Statement: Not applicable.

Data Availability Statement: Not applicable.

Acknowledgments: The authors are incredibly appreciative of the Ball Kings Industry's management, Focal point, Ludhiana, Punjab, India, for providing experimental set-up (s) and carbide dies.

Conflicts of Interest: The authors declare no conflict of interest.

\section{References}

1. Kunieda, M.; Nakagawa, T.; Higuchi, T. Devélopment of a polishing robot for free form surface. In Proceedings of the 5th International Conference on Production Engineering, Tokyo, Japan, 9-19 July 1984; pp. 265-270.

2. Saito, K.; Miyoshi, T.; Sasaki, T. Automation of polishing process for a cavity surface on dies and molds by using an expert system. CIRP Ann. 1993, 42, 553-556. [CrossRef]

3. Lu, R.; Minarro, L.; Su, Y.-Y.; Shemenski, R.M. Failure mechanism of cemented tungsten carbide dies in wet drawing process of steel cord filament. Int. J. Refract. Met. Hard Mater. 2008, 26, 589-600. [CrossRef] 
4. Jahan, M.; Rahman, M.; Wong, Y. A review on the conventional and micro-electro discharge machining of tungsten carbide. Int. J. Mach. Tools Manuf. 2011, 51, 837-858. [CrossRef]

5. Lilly, B.; Bailey, R.; Altan, T. Automated finishing of dies and molds: A state of the art review. CIRP Ann. 1988, 32, 75-90.

6. Saito, K.; Miyoshi, T.; Jeong, J. A dual-axis micro-finishing tool for free-form metal surface of a mold cavity. In Proceedings of the Proceedings Grinding Symposium (ASME Winter Annual Meeting), Miami, FL, USA, 17-22 November 1985; pp. $229-230$.

7. Kito, H.; Nishimoto, H.; Takai, Y.; Goto, A.; Hamada, H. The Analysis of Repeatability of Polishing Work Motion for a Cold Forging Die with Simple Axial Symmetric Form. In Proceedings of the International Conference on Applied Human Factors and Ergonomics, Los Angeles, CA, USA, 17-21 July 2017; pp. 415-423.

8. Tian, F.; Lv, C.; Li, Z.; Liu, G. Modeling and control of robotic automatic polishing for curved surfaces. CIRP J. Manuf. Sci. 2016, 14, 55-64. [CrossRef]

9. De Agustina, B.; Marín, M.M.; Teti, R.; Rubio, E.M.J.M. Analysis of force signals for the estimation of surface roughness during Robot-Assisted Polishing. Materials 2018, 11, 1438. [CrossRef]

10. Wang, K.B.; Dailami, F.; Matthews, J. Towards collaborative robotic polishing of mould and die sets. Procedia Manuf. 2019, 38, 1499-1507. [CrossRef]

11. Kohut, T. Surface finishing with abrasive flow machining. In Proceedings of the SME Technical Paper, Proc. 4th International Aluminium Extraction Technology Seminar, Washington, DC, USA, 11 April 1988; pp. 35-42.

12. Jain, R.K.; Jain, V.K.; Dixit, P.M. Manufacture. Modeling of material removal and surface roughness in abrasive flow machining process. Int. J. Mach. Tools 1999, 39, 1903-1923. [CrossRef]

13. Singh, S.; Shan, H.; Kumar, P. Wear behavior of materials in magnetically assisted abrasive flow machining. J. Mater. Proc. Technol. 2002, 128, 155-161. [CrossRef]

14. Walia, R.S.; Shan, H.S.; Kumar, P. Abrasive Flow Machining with Additional Centrifugal Force Applied to the Media. Mach. Sci. Technol. 2006, 10, 341-354. [CrossRef]

15. Jain, V. Abrasive-based nano-finishing techniques: An overview. Mach. Sci. Technol. 2008, 12, 257-294. [CrossRef]

16. Mali, H.S.; Manna, A. Optimum selection of abrasive flow machining conditions during fine finishing of $\mathrm{Al} / 15 \mathrm{wt} \% \mathrm{SiC}-\mathrm{MMC}$ using Taguchi method. Int. J. Adv. Manuf. Technol. 2010, 50, 1013-1024. [CrossRef]

17. Kenda, J.; Pusavec, F.; Kermouche, G.; Kopac, J. Surface integrity in abrasive flow machining of hardened tool steel AISI D2. Procedia Eng. 2011, 19, 172-177. [CrossRef]

18. Li, J.Y.; Liu, W.N.; Yang, L.F.; Liu, B.; Zhao, L.; Li, Z. The development of nozzle micro-hole abrasive flow machining equipment. Appl. Mech. Mater. 2011, 44, 251-255. [CrossRef]

19. Wang, A.C.; Chen, K.Y.; Cheng, K.C.; Chiu, H. Elucidating the Effects of Helical Passageways in Abrasive Flow Machining. Adv. Mater. Res. 2011, 264, 1862-1867. [CrossRef]

20. Xie, W.B.; Zhang, K.H.; Zhang, S.W.; Xu, B. Research on Abrasive Flow Machining for the outer rotor of cycloidal pump. Key Eng. Mater. 2013, 546, 50-54. [CrossRef]

21. Xu, Y.C.; Zhang, K.H.; Lu, S.; Liu, Z.Q. Experimental investigations into abrasive flow machining of helical gear. Key Eng. Mater. 2013, 546, 65-69. [CrossRef]

22. Mali, H.S.; Sambharia, J. Developing alternative polymer abrasive gels for abrasive flow finishing process. In Proceedings of the 5th International \& 26th All India Manufacturing Technology, Design and Research Conference (AIMTDR 2014), Guwahati, India, 12-14 December 2014; pp. 1-8.

23. Sarkar, M.; Jain, V.J. Nanofinishing of freeform surfaces using abrasive flow finishing process. Proc. Inst. Mech. Eng. Part B J. Eng. Manuf. 2017, 231, 1501-1515. [CrossRef]

24. Singh, S.; Ravi Sankar, M.; Jain, V.K. Simulation and experimental investigations into abrasive flow nano finishing of surgical stainless steel tubes. Mach. Sci. Technol. 2018, 22, 454-475. [CrossRef]

25. Butola, R.; Jain, R.; Bhangadia, P.; Bandhu, A.; Walia, R.; Murtaza, Q.J.M.T.P. Optimization to the parameters of abrasive flow machining by Taguchi method. Mater. Today Proc. 2018, 5, 4720-4729. [CrossRef]

26. Mohammadian, N.; Turenne, S.; Brailovski, V. Surface finish control of additively-manufactured Inconel 625 components using combined chemical-abrasive flow polishing. J. Mater. Proc. Technol. 2018, 252, 728-738. [CrossRef]

27. Sambharia, J.; Mali, H.S. Recent developments in abrasive flow finishing process: A review of current research and future prospects. Proc. Inst. Mech. Eng. Part B J. Eng. Manuf. 2019, 233, 388-399. [CrossRef]

28. Yunus, M.; Alsoufi, M.S. Application of Response Surface Methodology for the Optimization of the Control Factors of Abrasive Flow Machining of Multiple Holes in Zinc and AL/SICP MMC Wires. J. Eng. Sci. Technol. 2020, 15, 655-674.

29. Bhardwaj, A.; Ali, P.; Walia, R.; Murtaza, Q.; Pandey, S. Development of Hybrid Forms of Abrasive Flow Machining Process: A Review. In Advances in Industrial and Production Engineering; Springer: Berlin/Heidelberg, Germany, $2019 ;$ pp. 41-67.

30. Romanowski, M.; Łukianowicz, C.; Sutowska, M.; Zawadka, W.; Pimenov, D.Y.; Nadolny, K. Assessment of the Technological Quality of X5CRNI18-10 Steel Parts after Laser and Abrasive Water Jet Cutting Using Synthetic Index of Technological Quality. Materials 2021, 14, 4801. [CrossRef] [PubMed]

31. Sutowska, M.; Kapłonek, W.; Pimenov, D.Y.; Gupta, M.K.; Mia, M.; Sharma, S. Influence of Variable Radius of Cutting Head Trajectory on Quality of Cutting Kerf in the Abrasive Water Jet Process for Soda-Lime Glass. Materials 2020, 13, 4277. [CrossRef] [PubMed] 
32. Chen, C.T. Extensions of the TOPSIS for group decision-making under fuzzy environment. Fuzzy Sets Syst. 2000, 114, 1-9. [CrossRef]

33. Opricovic, S.; Tzeng, G.H. Compromise solution by MCDM methods: A comparative analysis of VIKOR and TOPSIS. Eur. J. Oper. Res. 2004, 156, 445-455. [CrossRef]

34. Farwaha, H.S.; Deepak, D.; Brar, G.S. Mathematical modeling and process parameters optimization of ultrasonic assisted electrochemical magnetic abrasive machining. J. Mech. Sci. Technol. 2020, 34, 5063-5073. [CrossRef]

35. Kumar, R.; Bilga, P.S.; Singh, S. Multi objective optimization using different methods of assigning weights to energy consumption responses, surface roughness and material removal rate during rough turning operation. J. Clean. Prod. 2017, 164, 45-57. [CrossRef]

36. Biscaia, R.V.B.; Dzulinski, A.C.; de Melo, E.L.; Braghini Junior, A. Comparison of EDM and laser trepanation micro-drilling processes using multiple-criteria decision analysis. Int. J. Adv. Manuf. Technol. 2021, 116, 2599-2612. [CrossRef]

37. Nguyen, H.P.; Pham, V.D.; Ngo, N.V. Application of TOPSIS to Taguchi method for multi-characteristic optimization of electrical discharge machining with titanium powder mixed into dielectric fluid. Int. J. Adv. Manuf. Technol. 2018, 98, 1179-1198. [CrossRef]

38. Kumar, R.; Dubey, R.; Singh, S.; Singh, S.; Prakash, C.; Nirsanametla, Y.; Królczyk, G.; Chudy, R. Multiple-Criteria DecisionMaking and Sensitivity Analysis for Selection of Materials for Knee Implant Femoral Component. Materials 2021, $14,2084$. [CrossRef] [PubMed]

39. Kumar, R.; Singh, S. Abrasive Flow Polishing of Tungsten Carbide Wire Drawing Die. Int. J. Appl. Eng. Res. $2011,6,499-510$.

40. Kumar, R.; Bilga, P.S.; Singh, S. Optimization of Active Cutting Power Consumption by Taguchi Method for Rough Turning of Alloy Steel. Int. J. Metall. Alloys 2020, 6, 37-45.

41. Udroiu, R.; Braga, I.C.; Nedelcu, A. Evaluating the Quality Surface Performance of Additive Manufacturing Systems: Methodology and a Material Jetting Case Study. Materials 2019, 12, 995. [CrossRef]

42. ISO 4288; Geometrical Product Specifications (GPS)—Surface Texture: Profile Method: Rules and Procedures for the Assessment of Surface Texture. ISO: Geneva, Switzerland, 1996.

43. Tripathy, S.; Tripathy, D.K. Multi-response optimization of machining process parameters for powder mixed electro-discharge machining of H-11 die steel using grey relational analysis and topsis. Mach. Sci. Technol. 2017, 21, 362-384. [CrossRef]

44. Vaid, S.K.; Vaid, G.; Kaur, S.; Kumar, R.; Sidhu, M.S. Application of multi-criteria decision-making theory with VIKOR-WASPASEntropy methods: A case study of silent Genset. Mater. Today Proc. 2022, 50, 2416-2423. [CrossRef]

45. Jatin; Kaur, S.; Goel, P.; Randhawa, K.S.; Channi, H.K. Selection of water purifier with TOPSIS using impartial preferences by entropy technique. Mater. Today Proc. 2022, 50, 1389-1396. [CrossRef]

46. Kumar, R.; Bilga, P.S.; Singh, S. Optimization and Modeling of Active Power Consumption for Turning Operations. In Proceedings of the ISME 19th Conference on Advances in Mechanical Engineering (Mechanical Systems and Sustainability), Jalandhar, India, 20-22 December 2018; pp. 1-16.

47. Singh, G.; Singh, S.; Prakash, C.; Kumar, R.; Kumar, R.; Ramakrishna, S. Characterization of three-dimensional printed thermalstimulus polylactic acid-hydroxyapatite-based shape memory scaffolds. Polym. Compos. 2020, 41, 3871-3891. [CrossRef]

48. Chodha, V.; Dubey, R.; Kumar, R.; Singh, S.; Kaur, S. Selection of industrial arc welding robot with TOPSIS and Entropy MCDM techniques. Mater. Today Proc. 2022, 50, 709-715. [CrossRef]

49. Kumar, R.; Kaur, S. Multi Attribute Decision Making Approach to Select Microwave Oven with TOPSIS Method. In Proceedings of the 7th International Conference on Advancements in Engineering and Technology (ICAET-2019), Sangrur, India, 15-16 March 2019; pp. 357-361.

50. Antil, P.; Singh, S.; Manna, A. Experimental Investigation During Electrochemical Discharge Machining (ECDM) of Hybrid Polymer Matrix Composites. Iran. J. Sci. Technol. Trans. Mech. Eng. 2020, 44, 813-824. [CrossRef]

51. Sidhu, A.S.; Singh, S.; Kumar, R.; Pimenov, D.Y.; Giasin, K. Prioritizing Energy-Intensive Machining Operations and Gauging the Influence of Electric Parameters: An Industrial Case Study. Energies 2021, 14, 4761. [CrossRef]

52. Rajamanickam, S.; Prasanna, J.; Chandrasekhara Sastry, C. Analysis of high aspect ratio small holes in rapid electrical discharge machining of superalloys using Taguchi and TOPSIS. J. Braz. Soc. Mech. Sci. Eng. 2020, 42, 99. [CrossRef]

53. Kenda, J.; Kermouche, G.; Dumont, F.; Rech, J.; Kopac, J. Investigation of the surface integrity induced by abrasive flow machining on AISI D2 hardened steel. Int. J. Mater. Prod. Technol. 2013, 46, 19-31. [CrossRef]

54. Becker, W.T.; Shipley, R.J. Wear Failures. In Failure Analysis and Prevention; Becker, W.T., Shipley, R.J., Eds.; ASM International: Novelty, OH, USA, 2002; Volume 11, p. 25.

55. Cheng, K.-C.; Huang, C.-Y.; Hung, J.-C.; Wang, A.; Lin, Y.-C. Study of the Transcription Effects of Pressing Dies with Ultrasonic Polishing on Glass Molding. Processes 2021, 9, 2083. [CrossRef]

56. Lin, B.; Jiang, X.-M.; Cao, Z.-C.; Huang, T. Development and theoretical analysis of novel center-inlet computer-controlled polishing process for high-efficiency polishing of optical surfaces. Robot. Comput.-Integr. Manuf. 2019, 59, 1-12. [CrossRef]

57. Singh, S.; Shan, H.S. Development of magneto abrasive flow machining process. Int. J. Mach. Tools Manuf. 2002, 42, 953-959. [CrossRef]

58. Dixit, N.; Sharma, V.; Kumar, P. Research trends in abrasive flow machining: A systematic review. J. Manuf. Processes 2021, 64, 1434-1461. [CrossRef] 